\title{
Ensuring students' wellness: resources and demands in higher education
}

\author{
Inna I. Ikatova ${ }^{1,{ }^{*}}$, Irina $V$. Barynkina ${ }^{1}$, and Lyubov V. Amelina ${ }^{1}$ \\ ${ }^{1}$ I.G. Petrovsky Bryansk State University, Bryansk, Russia
}

\begin{abstract}
New technologies are changing higher education at an unprecedented scale, therefore to get a competitive edge societies round the world are trying to find new ways to meet emerging challenges by optimizing learning outcomes. The aim of the present article is to study the mitigating role of resources available to university students in the relation to demands, evaluate and compare their stress levels during Covid-19 lockdown and in-classroom learning using Demand-Induces Strain Compensation Model at Bryansk State University. Findings showed high stress levels during three months of remote learning, since physical and cognitive demands were poorly counterbalanced with relevant resources. Inperson education demonstrated lower stress levels due to fewer demands and better resources in physical and emotional aspects. As to a cognitive aspect, the moderating role of resources was still insufficient, though the rate of cognitive demands was lower, compared to the remote learning. Consequently, it is essential to achieve an equilibrium between demands and matching resources to ensure students' wellness. A range of didactic possibilities has been offered within the blended learning paradigm to enhance interaction, collaboration, confidence of students as independent and active learners. Fading techniques that encourage learners to become autonomous technology users by gradually removing prompts and making tasks more challenging have proved to be successful.
\end{abstract}

\section{Introduction}

The traditional pedagogical paradigm as we have generally understood it is unable to satisfy requirements of the present-day society [Rozin, 1997]. Transmitting knowledge, skills and cultural values of the previous generations onto a new one is outdated as new challenges to the global community emerge daily. To get a competitive edge societies around the world are trying to find new ways of imparting knowledge and managing data. Advancement of information is a global social process when collecting, accumulating, creating, processing, storing, sharing and using information becomes a dominant activity in any public production sector. It involves advanced micro-processing and computational technologies as well as diverse information sharing tools [Bim Bad, 2002]. Education is just another area experiencing radical changes to meet growing needs of the global community. According to G. Kress, both teachers and methodologists should aim at using a great diversity of multiple

\footnotetext{
* Corresponding author: ikatova_inna@mail.ru
} 
resources for making meaning of modes in multimodal approaches creating semiotically robust environments for learning. The designs for studying have to be adequate for the curriculum - the matter taught and pedagogy - the social relations in environments of learning and teaching [Kress, 2017].

Mainly three issues have prompted the present research. Firstly, most methodologists focus on modes of knowledge delivery by putting emphasis on teaching rather than learning. As technological revolution is drastically transforming traditional teaching at an unprecedented speed many educators incorporating technologies into classroom activities have not yet had enough time or opportunity to reflect on how they contribute to learning outcomes. Therefore, the learning experience should be highlighted.

Secondly, implications for learners ought to be assessed not only in terms of academic achievements but also regarding learners ' mental health and well-being. Students at Bryansk State University like all their peers in the countries hit by Coronavirus infection had to move to online learning for more than three months in 2020. For most of them (if not for everybody), it was a stressful period burdened by uncertainty, anxiety and radical change in educational environment. Even before Covid-19 pandemic the scientific evidence was conclusive that the level of stress at universities had increased compared to the previous century [Williams (eds) 2017, Mudrak (eds), 2018]. High educational load, little leisure time, tight deadlines, lack of psychological support, domestic conflicts and other causes are usually listed among most common factors [ibid]. Consequently, scientists point out to deteriorating health, poor life satisfaction and low self-esteem [Mark, Smith, 2018]. The situation is often made worse by worries about academic performance, career, interpersonal problems, financial difficulties, the necessity to combine studies with paid jobs [Chacon-Cuberos (eds), 2019].

Thirdly, since online learning is increasingly becoming universal and a lockdown might happen again its effects on students' well-being should be thoroughly studied. Though existing theoretical background on evaluating stress levels and the ways to reduce it has been so far applied only to investigating stress in a work related setting, we believe it could be successfully used to research the same phenomenon among students. Most basic activities of university students can be classified as 'work', though students are not employed [Chambel, Curral, 2005; Rahmati, 2015]. Their daily routine (problem solving, verbal communication, working on projects, researching etc.) and the nature of stress they are exposed to are similar to those that hired employees experience at their workplace.

To summarize, since there is little research as yet into students' working setting both digital and in-classroom and stress level related to it due to a novel coronavirus lock down, the present paper is an attempt to fill in this gap.

\section{Theoretical background}

According to present-day learning-related stress models students' academic progress can be largely explained by at least the following characteristics: course and teacher's requirements and available resources [De Jong, Dormann, 2017]. Learning demands can be determined as tasks that call for short or long-term efforts and range from solving problems while experiencing intense emotions to commuting or dealing with technical problems. Learning resources are assets a person has an access to in their studies (e.g. data, devices, people etc) and that can be used to meet course and teacher`s requirements [Van den Tooren et al., 2011]. Concrete examples of learning resources include support from fellow-students and educators and equipment. So far a lot of research has been done into work-related stress and the findings have revealed key characteristics which are rather broad and therefore could be applicable to a variety of job settings. For example, R. Karasek and T. Theorell's job demand-control model states that high demands and low decision latitude or intense micromanagement make 
any job stressful [Karasek, Theorell, 2001]. A different study by E. Demerouti resulted in demands-resources model that showed interrelationship between employee's wellness and motivation and the demands and resources that define their job [Demerouti, 2014]. This approach enjoyed significant support of many scholars, HR managers and consultants. However, many theorists believe that any new research should specify job features and identify practical measures mitigating the stress and suggest that a specific type of social support should target a definite workplace demand [Cohen, Wills, 1985; Duckworth, Peterson, Matthews, 2003].

A theoretical model that has been created to clarify a mitigating role of a particular job resource in the interaction between specific workplace demands and specific well-being issues is the Demand-Induces Strain Compensation Model (DISC) [De Jonge, Dorman, 2006]. Unlike previous models, it asserts that a mitigating impact of job resources is closely connected with the notion of 'correspondence' between job demands and job resources. In detail, this approach involves two fundamental assumptions: the multidimensionality principle and the triple-match principle [De Jonge, Dormann, 2017]. The multidimensionality principle was first described by De Jonge and Dormann in 2003 and states that workplace demands, resources and health consist primarily of physical, emotional and cognitive elements. Workplace demands can be mainly physical (e.g. having to sit or stretch a lot), cognitive (e.g. facing a complexity of a task, requiring high levels of concentration) or emotional (e.g. having to deal with frustration, failures or conflicts). A comparable differentiation can be applied to resources which can be primarily physical (e.g. availability of necessary material assets), cognitive (e.g. independence in decision-making process) and emotional (e.g. receiving encouragement from others). Lastly, the model identifies health outcomes of physical, cognitive and emotional nature that can be negative (e.g. general health complaints, poor concentration, depression,) or positive (e.g. high energy levels, great expertise, strong motivation).

The second principle is called triple match principle [De Jonge, Dormann, 2006]. It proposes that the mitigating role of resources is salient if demands, resources and outcomes are based on matching elements, i.e. the moderating effect of resources is based on the question of correspondence - a complementary fit between resources and demands [Van den Tooren et al., 2011] with resources providing the balancing power required to cope with particular demands. For example, if a student were struggling with getting access to her Moodle account the appropriate instrumental technical help from fellow students or a teacher would provide the optimal strength to deal with this task. A different type of social support, like words of sympathy and understanding would have less constructive effect in a given situation. Thus, in the first case resources demonstrate a complementary fit to demands, which moderates the negative effect of stress.

Furthermore, the triple match principle suggests that it is not enough for demands and resource to correspond; they should also promote well-being outcomes. Moreover, big demands trigger positive emotional response if workers have ample matching types of resources [De Jonge (eds), 2019], because if they have substantial resources, they could try different ways of solving a problem. The matching combination of demands and resources can lead to beneficial outcomes, like better creativity, inspiration or competence [ibid]. For sample, a cognitively challenging assignment can stimulate inventiveness, vitality and proficiency only if appropriate cognitive resources (e.g. availability of information) are present.

The DISC model states that workers will first resolve demands using easily accessible corresponding resources [De Jong, Dormann, 2003, 2017], but in the case they are not available employees will turn to other resources that are less fitting. If these less matching resources are exhausted, workers will then turn to resources that do not correspond to their demands. Along with triple matches, the DISC model explores two types of double-matches 
that are worse when it comes to complementary fit, i.e. only two out of three elements match. The example is the study of health care workers by De Jonge revealed a double match between emotional demands (e.g. frustrated patients or bereaved relatives) and emotional resources (e.g. high quality counselling) in exploring the prediction of creativity.

According to the above-mentioned model, there is an occurrence of non-match between all elements, and if this is the case, then mitigating effects of resources are less likely to have a place. This is the situation, when demands, resources and outcomes are essentially different. To sum up, the main finding of De Jong, Dormann is that the likelihood of finding mitigating impact of resources increases as the level of correspondence between resources, outcomes and demands increases [De Jonge, Dormann, 2017].

\section{Method}

\subsection{Participants and design}

This survey study was conducted using online questionnaires for students of the Translation Studies department at Bryansk State University to fill out. The total sample involved 98 respondents. They received a message containing a questionnaire in June 2020 when they had been studying remotely for three months on Moodle-based learning Management System. They had to respond to the same questionnaire in November 2020 after they had been back to their classrooms for three months. The majority of the young people ( $89 \%)$ were female. The participants were asked to respond to questions within 2 weeks. Mean age of students was 20.7 years $(\mathrm{SD}=3.8)$. All students had a Russian nationality. Gender was not a controlled characteristic in the survey.

\subsection{Moodle-based Learning Management System}

One of the most common ways to deliver educational services to students online and create a productive learning environment is Moodle-based learning Management System (LMS). It is indispensable when distance learning is the only option and has undeniably demonstrated its advantages during Coronavirus lockdown period. The top benefits of the LMS are 1) information and course content storage; 2) sharing information among users; 3) communication and cooperation between a teacher and students; 4) assessments of progress and end results; 5) tools for monitoring and reporting student's progress; 6) personalized feedback to submitted papers using pre-constructed statements; 7) interactive learning.

The BigBlueButton, an interactive tool enabling students to chat through video conferencing can be set up for either private or public exchange. A speaker can upload PowerPoints or other files, share presentations using whiteboards. There is an emoji feature for users to give feedback or ask questions. Webcam facility and desktop sharing allows for closer contacts and therefore better interaction. A BigBlueButton session can be played back if required. Moodle LMS enables effective collaboration between students and a teacher providing specific tools: individual, group chats or a forum format. Any information could be transmitted via "Alert" tool available to all users. However, both students and teachers rarely use this feature for the following reasons: 1) social network is a more convenient and traditional way of interaction; 2) unlike messaging on social networking sites Moodle LMS usually has no notifications app on students' mobile phones so students access the platform only when they choose to. The key word here is flexibility, since this learning management service in many cases provides an immediate feedback. If a student's progress is low a teacher can interfere at any stage and replace or alter tasks in a required manner: offer a different combination of exercises, loosen the timeframe or increase the number of attempts to ensure 
more practice. Thanks to the access to identified mistakes students can (with or without a teacher's guidance) analyze their problem areas and work on them at home. Moreover, students are encouraged to research the relevant material since any Internet resource can appear on Moodle.

\section{Instruments}

Resources and demands during in-classroom and distant learning were calculated using the version of the reliable DISC questionnaire [De Jonge (eds), 2009]. It includes six scales for physical, emotional and cognitive demands and resources. Each scale entails four statements and each statement is rated on a five-point frequency scale ranging from 1 (never) to 5 (always). Example statements for demands during the study are I face complex assignments at my Translation class (cognitive element). I feel emotionally drained by the end of my classes (emotional element).

Sample statements of resources for studying are I have the opportunity to choose from a selection of assignments that I see as relevant (cognitive element). I get psychological support from others when I am upset (emotional element). Or I have the opportunity to have a break when I am tired of sitting (physical element). Each statement had an additional box 'Elaborate' for students to submit comments, if they wished to explain or comment on specific details.

The procedure in this survey study involving students was conducted within ethical standards of Bryansk State University and informed consent was received from all participants who took part in this research.

\section{Results}

Table 1 demonstrates considerable differences between demands laid on students during online studies and available resources.

Table 1. Online learning.

\begin{tabular}{|cc|c|}
\hline Demands & Resources \\
\hline \multicolumn{3}{|c|}{ Physical } \\
\hline 4.4 & & 2.4 \\
\hline \multicolumn{3}{|c|}{ Emotional } \\
\hline 3.1 & & 2.9 \\
\hline \multicolumn{3}{|c|}{ Cognitive } \\
\hline 4.6 & & 3.1 \\
\hline
\end{tabular}

Firstly, we can see, that demands in a physical aspect far exceed resources. Emotional outcomes are also negatively related to demands which students rated lower compared to physical ones. They also had more emotional support available, unlike in case with physical resources. Interestingly, most students pointed to high cognitive demands during online learning, but rated available resources as insufficient.

Table 2 shows students ' responses to the same questionnaire after three months of inclassroom learning. 
Table 2. In-classroom learning.

\begin{tabular}{|c|c|}
\hline Demands & Resources \\
\hline \multicolumn{2}{|c|}{ Physical } \\
\hline 2.6 & 3.8 \\
\hline \multicolumn{2}{|c|}{ Emotional } \\
\hline 3.4 & 4.2 \\
\hline \multicolumn{2}{|c|}{ Cognitive } \\
\hline 4.3 & 3.9 \\
\hline
\end{tabular}

Physical resources in table 2 significantly outweigh demands revealing strong negative relation. The same goes to the ratio between emotional demands and resources. The results concerning the cognitive aspect reveal positive relation between demands and resources.

As the table 3 shows, the number of items submitted to 'Elaborate' boxes reveals a significance discrepancy between the amount of comments made during the quarantine and post-lockdown learning.

Table 3. Students` comments on the online learning mode.

\begin{tabular}{|c|c|c|}
\hline Aspects & Demands & Resources \\
\hline $\begin{array}{l}\text { The number of filled in } \\
\text { boxes }\end{array}$ & 534 & 479 \\
\hline Physical & $\begin{array}{l}\text { 'Continuous, often monotonous } \\
\text { work on the computer' }(99 \%) \\
\text { 'Tired eyes' }(73 \%) \\
\text { 'Poor internet connection and } \\
\text { difficulties in navigating LMS' } \\
(49 \%\}\end{array}$ & $\begin{array}{l}\text { 'did not have to commute' } \\
(91 \%) \\
\text { 'was able to have delicious } \\
\text { meal' }(63 \%) \\
\text { 'was able to space out some of } \\
\text { the assignments' }(53 \%)\end{array}$ \\
\hline Emotional & $\begin{array}{l}\text { 'Reduced interaction between } \\
\text { teachers and students as well as } \\
\text { between students' }(95 \%) \\
\text { 'Reduced variety } \\
\text { assignments' }(69 \%) \\
\text { 'Lack of encouragement and } \\
\text { psychological support' }(68 \%) \text { ' } \\
\text { 'Deadlines for assignments" } \\
(67 \%)\end{array}$ & $\begin{array}{l}\text { 'The opportunity to spend a lot } \\
\text { of time with one's family' } \\
\text { ( } 56 \%) \\
\text { 'Permission to have almost } \\
\text { unlimited access to online } \\
\text { resources' }(43 \%) \\
\text { 'Permission to switch off the } \\
\text { camera during some classes' } \\
(13 \%)\end{array}$ \\
\hline Cognitive & $\begin{array}{l}\text { 'Poor concentration, memory, } \\
\text { lack of good analytical skills' } \\
(63 \%) \\
\text { 'Inability to cope with } \\
\text { homework due to its big amount } \\
\text { or complexity because of low } \\
\text { overall cognitive abiliity' } \\
(59 \%) \text { 'Poor preparedness to work } \\
\text { independently' }(32 \%)\end{array}$ & $\begin{array}{l}\text { 'The Internet access' }(100 \%) \\
\text { 'The BigBlueButton Chatroom } \\
\text { enabling to ask questions' } \\
(51 \%) \\
\text { 'Learning management service } \\
\text { provides an immediate } \\
\text { feedback' }(24 \%)\end{array}$ \\
\hline
\end{tabular}

\section{Online learning}

Among upsetting physical aspects most respondents pointed out fatigue because they found it difficult to sit in front of the computer for hours with 5-10 minute breaks after every 45 minutes, though a 40 minute-lunch break after three hours of studying was provided. According to students, breaks were often occupied to prepare papers or computer files for the next class. The available resources involved going out to another room or a garden or standing 
with closed eyes. They also pointed out that being at home solved the problem of having a proper meal.

The elaboration of emotional demands indicated reduced interaction time because a certain amount of classes were designed as tests, presentations or doing exercises outside the BigBlueButton feature. Students often found it impossible to clarify their individual problem areas with a teacher as they were concerned about other students' needs and were shy of monopolizing teacher's time. These were the most frustrating aspects. Contributions regarding cognitive demands uncovered insufficient skills in autonomous learning with some students. Though they were welcome to use the Internet resources most of the time, they chose to rely on a teacher to explain some tasks or resolve difficulties. All students mentioned online materials as very helpful, however, they did not see them as completely satisfying for their needs.

Table 4. Students` comments on the in-classroom learning mode.

\begin{tabular}{|c|c|c|}
\hline Aspects & Demands & Resources \\
\hline $\begin{array}{l}\text { The number of filled in } \\
\text { boxes }\end{array}$ & 326 & 275 \\
\hline Physical & $\begin{array}{l}\text { 'Daily commute is very tiring' } \\
(85 \%) \\
\text { 'Getting up early is a problem' } \\
(82 \%) \\
\text { 'Inconvenient time-table' } \\
(68 \%)\end{array}$ & $\begin{array}{l}\text { 'Interactive and diverse } \\
\text { activities stimulate productivity } \\
\text { and keep everybody interested' } \\
(91 \%) \\
\text { 'Competing with group mates } \\
\text { and deadlines do not allow } \\
\text { being lazy' (56\%) } \\
\text { 'Good time management skills } \\
\text { keep energy levels up" ( } 43 \%)\end{array}$ \\
\hline Emotional & $\begin{array}{l}\text { 'Always feel anxious when I } \\
\text { have to speak in front of the } \\
\text { audience' }(72 \%) \\
\text { 'Have to do assignments even } \\
\text { if I find them boring and } \\
\text { useless' }(42 \%) \\
\text { 'Always worry about lagging } \\
\text { behind my group mates' ( } 35 \%)\end{array}$ & $\begin{array}{l}\text { 'My group mates are very } \\
\text { responsive and understanding' } \\
(74 \%) \\
\text { 'I know I can always ask my } \\
\text { teacher for help' }(68 \%) \\
\text { 'Traditional learning helps me } \\
\text { stay within my comfort zone/ } \\
(48 \%)\end{array}$ \\
\hline Cognitive & $\begin{array}{l}\text { 'I often do not have enough } \\
\text { time to do my homework' } \\
(68 \%) \\
\text { 'I have difficulty in } \\
\text { memorizing a lot of new words } \\
\text { and information' }(56 \%) \\
\text { 'Teachers sometimes do not } \\
\text { comment on our answers and it } \\
\text { hinders the progress' }(23 \%)\end{array}$ & $\begin{array}{l}\text { 'There are a lot of opportunities } \\
\text { for practice' }(95 \%) \\
\text { 'A lot of assignments are } \\
\text { thought-provoking } \\
\text { stimulating' }(72 \%) \\
\text { 'Face-to-face and interaction } \\
\text { enhances mental capabilities } \\
\text { and leads to self-improvement' } \\
(35 \%)\end{array}$ \\
\hline
\end{tabular}

\section{Off-line learning}

More than half of the students see a daily commute very tiring. Others refer to an inconvenient time-table with classes finishing after 5 p.m. Nevertheless, there are also good reserves to combat physical fatigue, like the opportunity to leave the classroom any time they felt any physical discomfort or relax during the break. They did not have to stare at the computer screen for hours.

Among the most unpleasant emotional demands are feeling anxious when they have to speak in front of the class, lagging behind the group mates when doing translation assignments or having misunderstanding with teachers or other students. All respondents 
have support from teachers and peers in case of difficulties, encouragement when facing challenges and praise when they have succeeded.

The survey participants find learning demands quite high citing poor memory or inadequate analytical skills, a big amount of time-consuming homework, lack of motivation to do some types of assignments. Others name excellent memory, good analytical skills, and availability of teachers as cognitive resources.

The review of four tables gives a good idea in which areas of learning stress levels go up. Students report increased physical demands with fewer resources during remote studying. The same goes in regards to a cognitive aspect. The latter finding might come as a surprise because teachers generally used Hyperlink features in Moodle LMS to provide access to relevant information that could answer the questions students might have. As to emotional outcomes, demands only slightly exceed resources, which means that negative feelings overall do not dominate the learning process - it is rather physical and cognitive demands that should be addressed in terms of levels and resources.

Off-line learning is not stress-free either. Students still struggle with cognitive demands that are not fully balanced by resources. However, emotional outcomes and physical demands differ from resources figures on a small scale.

\section{Discussion}

Due to advancement of technology, online learning has become increasingly popular and it is tempting for both educators and learners to take into account only its great potential in providing flexible cost-effective access to educational content and teaching from anywhere and at any time. As this survey study clearly demonstrates, automatically moving activities that have been successful in the classroom into digital environment does not result in immediate gain even with the user-friendly Moodle LMS. Though research results uncovered high stress levels in online learning, we cannot reject it as completely inadequate, because if students are to take part in international research and worldwide academic activities, they have to be able to use online platforms and effectively find resources to meet international standards.

Though poor Internet connection and technical failures in individual computers are outside teachers' control, the resources to train students in a more effective Moodle LMS navigation can be easily supplied. Physical demands involving exhaustion from continuous sitting and eyes tiredness could be counterbalanced with breakout rooms that can be designed considering students' needs and preferences. They have proved to break monotony, allow exchange of meaningful idea and provide relaxation to the staff in many companies during lockdown.

To successfully meet challenges regarding emotional outcomes, educators can organize tutorials. They can be arranged for individuals who are really struggling, for students who benefit from the same teaching/learning style - the combinations could be infinite. Teachers could also consider relaxing deadlines for some students to give them time so that they could master time-management skills. Online interaction can hardly be equal to a personal contact, and, unfortunately, it is increasingly getting common and probably soon will not mean leaving one's comfort zone, but become a dominant way of communication.

Dealing with cognitive demands suggests mastering techniques that enhance memorization, methods for better analysis as well as training in self-organization to improve concentration, creativity and lateral thinking, including various types of assignments and diversifying timeframes might help too.

We should also bear in mind that high stress levels reported by students concerning online learning might have been brought about by externally imposed pressure that had little to do with the nature of the online mode. Moreover, the research findings prove that the 
combination of individual characteristics, like being psychologically well adjusted, conscientious, persistent and goal-oriented, can help less cognitively gifted students succeed despite structural and systemic faults [Graham, Dziuban, 2008; Chew, Jones, Turner, 2008].

Significantly, the same measures that apply to improving online learning outcomes can be taken to optimize in-classroom learning, i.e. using a differentiated approach in terms of activities, diversifying time frames and teaching students effective learning techniques. Students are also meant to have sufficient skills for autonomous learning: either individually or in pairs and groups, which means developing cognitive competence (when students set and achieve learning goals and monitor their own progress), communicative competence (managing their interaction in a foreign language in a specific situation) and instrumental competence (the ability to use technologies for enhancing communicative skills to complete required tasks and demonstrate the results) [Buckner, Morsk, 2017]. The survey results revealed that traditional classroom interaction is indispensable when learning a foreign language: verbal communication is an area still monopolized by humans rather than by technologies. Furthermore, most creative types of tasks including interpreting and translation require a direct teacher`s involvement: no LMS is able to assess open ended assignments due to the excessive variability of options.

Thus, didactic possibilities that boost interaction and collaboration both digitally and physically, expand all types of resources, individualize learning, broaden positive student's experience might include following activities that have been tested in Bryansk State University. They worked, because they encouraged students to take a pro-active approach, offered variety, challenge and flexibility.

E-interaction implies several options: at the beginning of a class, a student gets a technological card with the information about practical tasks s/he is going to complete. The teacher designs this card taking into account the course content, student's needs and abilities. The card specifies if s/he can work independently, deciding on the order, number of the tasks and other details, or stick close to teacher's instructions. Practice can entail settings built into Moodle program: matching, open/cloze, multiple choice, drag and drop, select missing words/phrases, essays. The option embedded answers allows a teacher to create tasks targeting several skills: integrated writing/listening, a post-listening text review, incorporating if necessary assignments for interpreting or translation.

The key word here is flexibility, since this learning management service in many cases provides an immediate feedback. If a student's progress is low a teacher can interfere at any stage and replace or alter tasks in a required manner: offer a different combination of exercises, loosen the timeframe or increase the number of attempts to ensure more practice. Thanks to the access to identified mistakes students can (with or without a teacher's guidance) analyze their problem areas and work on them at home. Moreover, students are encouraged to research the relevant material since any Internet resource can appear on Moodle.

Though the described approach offers invaluable opportunities for solo learning, it does not exclude an active role of a teacher. Some students have sufficient skills to plan their own online learning, but most of them require teacher's support, that is why the interactional mode student - hosting service - teacher is seen as most effective since learners are meant to work with the native and foreign languages.

After a new vocabulary, speech or translation patterns have been learned and consolidated in a number of exercises, a collaborative interaction approach can be safely taken without worrying that users will be struggling for words and structures that ensure smooth communication or interpreting. Advanced learners are normally left to their own devices with an active record button in Forum feature. Later a teacher, speakers or the rest of the students could listen to the recorded interaction and comment on the mistakes, and practice quality 
assessment, which contributes greatly to an analytical and critical approach in learning activities.

At this stage the same ability groups or pairs are preferable, since students feel safer in a non-challenging environment. As their confidence in interpreting or discussing a course topic is growing, they can swap communication partners. Full understanding of group dynamics helps a teacher optimize this process either relying on students ' preferences or suggesting the most productive options. During this student-to-student(s) interaction in which web resources or recorded material is used a teacher can plug in at any time and listen-in to get an idea of students ' progress or guide them if in trouble.

One of the activities that offers numerous benefits in terms of language learning, speaking, interpreting, creative writing etc. is a video-case. Prior to watching it, students (if they wish) could familiarize themselves with vocabulary that might present a problem and decide on the most effective ways to complete the case: suggested options are presented on the screen and can be referred to or edited by learners. Thus, at the very beginning students become active participants of the learning process by making informed individual decisions. While-watching activities might include interpreting practice or predicting what will happen next. By witnessing a challenging situation students get involved into it, relate to film characters and empathize with them. After-watching activities could focus on a problem discussion, research and investigation, role-play, conducting surveys, or blogging. Rather that assuming a traditional role of a mentor the teacher makes students active designers of their education where they choose whether to work individually, in pairs or groups and the way they provide feedback. In case students are opposing the idea of collaborative learning a teacher could create information gaps distributing missing facts among group members so that they have to work together to complete the project.

To ensure the most effective interaction in class, educators should 'keep open mind and concentrate on learning experience', be pragmatic and select those tasks that are best suited to students and learning goals [Krasnova, c. 2015].

All things considered, the following strategies can be suggested:

- blended learning, where students are supported both by technologies and a teacher;

- fading techniques, that help learners become independent technology users by gradually removing prompts and making tasks more challenging;

- collaboration (students are encouraged to cooperate while completing selected assignments);

- monitoring progress and introducing changes to optimize learning.

\section{Conclusion}

The paper has been a result of the survey, analyzing students' learning experiences, evaluating their stress levels within the promising theoretical framework of DISC model. It suggests practical ways of maintaining a proper balance of demands and resources in the academic context. The findings might contribute to better teaching and learning outcomes, lowering stress levels, boosting confidence and self-esteem, which are vital for mental and physical health. Online learning either remote or blended is here to stay and the issue of the adequate computer mediated education is a pressing problem that requires further research by applying alternative methods and approaches, controlling different variables (e.g. gender, year, IQ etc.) and using a specific kind of activities. The challenge is vastly context dependent, but as many efforts as possible should be made, because students` well-being relies on it. 


\section{References}

1. R. Chacon-Cuberos, E.M. Olmedo-Moreno, A.J. Lara-Sanchez et al., Studies in Higher Education 7(23) (2019)

2. M.J. Chambel, L. Curral, Applied Psychology 54(1), 135-147 (2005)

3. S. Cohen, Wills, T.A. Psychological Bulletin 98(2), 310-357 (1985) https://doi.org/10.1037/0033-2909.98.2.310

4. A.L. Duckworth, C. Peterson, M.D. Matthews, D.R. Kelly, Journal of Personality and Social Psychology 92(6), 1087-1101 (2007)

5. M. Van den Tooren, J. De Jonge, C. Dormann, New challenges for a healthy workplace in human services (Rainer Hampp Verlag, 2011)

6. J. Mudrak, K. Zabrodska, P. Kveton et al., Research in Higher Education 59(3), 325348 (2018) https://doi.org/10.1007/s11162-017-9467-x

7. R.A. Karasek, T. Theorell, Healthy work (Basic Books, 1990)

8. E. Demerouti, C. Dormann, An introduction to contemporary work psychology (WileyBlackwell, 2014)

9. J. De Jonge, C. Dormann, Occupational stress in the service professions (Taylor \& Francis, 2003)

10. J. De Jonge, C. Dormann, Journal of Applied Psychology 91(6), 1359-1374 (2006) https://doi.org/10.1037/0021-9010.91.5.1359

11. J. De Jonge, C. Dormann, An introduction to work and organisational psychology: An international perspective (Wiley-Blackwell, 2017)

12. J. De Jonge, C. Dormann, N. Van Vegchel et al., DISQ 2.1: The DISC Questionnaire English Version 2.1 (Eindhoven University of Technology, 2009)

13. J. De Jonge, M.C.W. Peeters, T.W. Taris, International Journal of Environmental Research and Public Health 16(16), 2893 (2019)

14. Z. Rahmati, Procedia - Social and Behavioral Sciences 171, 49-55 (2015) https://doi.org/10.1016/j.sbspro.2015.01.087

15. G. Williams, K. Thomas, A.P. Smith, Psychology 08(12), 1919-1940 (2017)

16. B. Bim-Bad, Encyclopedia of Pedagogy (Moscow, Bolshaya rossiyskaya encyclopedia, 2002)

17. V. Rozin, Socio-political journal 3, 145-152 (1997)

18. G. Kress, The Image in the English Language Teaching (Malta, ELT Council, 2017) https://www.teachingenglish.org.uk/article/image-english-language-teaching

19. K. Buckner, K. Morsk, Research in Learning Technologies 7(1), 45-68 (2017)

20. T. Krasnova, Procedia - Social and Behavioral Sciences 166, 399-403 (2015) DOI:10.1016/j.sbspro.2014.12.543

21. C.R. Graham, C.D. Dziuban, Blended Learning Environments. Handbook of Research on Educational Communications and Technology (Mahwah, Lawrence Earlbaum Publ., 2008)

22. E. Chew, N. Jones, D. Turner, Critical Review of the Blended Learning Models Based on Maslow's and Vygotsky's Educational Theory' in Hybrid Learning and Education (Berlin, Springer Verlag Publ., 2008) DOI:10.1007/978-3-540-85170-7_4

23. G. Mark, A.P. Smith, Advances in Social Sciences Research Journal 5(2), 238-247 (2018) 